\title{
Epidermal Nevus
}

National Cancer Institute

\section{Source}

National Cancer Institute. Epidermal Nevus. NCI Thesaurus. Code C4088.

A benign, pigmented skin growth caused by an overg rowth of the epidermis. It is typically seen at birth, but can develop in early childhood or later in life. Most cases are sporadic, but familial patterns of inheritance have been observed. 